\title{
COMPARATIVE EFFECTS OF BRODIFACOUM ON RATS AND POSSUMS
}

\author{
K.E. LITTIN ${ }^{1}$, C.E. O’CONNOR ${ }^{2}$ and C.T. EASON ${ }^{2}$ \\ ${ }^{1}$ Animal Welfare Science and Bioethics Centre, Institute of Food, Nutrition and Human \\ Health, Massey University, Private Bag 11-222, Palmerston North, New Zealand \\ ${ }^{2}$ CENTOX Centre for Environmental Toxicology, Landcare Research, \\ PO Box 69, Lincoln, New Zealand
}

\begin{abstract}
The anticoagulant brodifacoum is widely used overseas as a rodenticide, and in New Zealand to control rodents and brushtail possums (Trichosurus vulpecula). The efficacy, behavioural and pathological changes and times to death were compared between Norway rats (Rattus norvegicus) and brushtail possums poisoned with brodifacoum. Caged animals were given brodifacoum in wax or cereal baits, observed for signs of toxicosis and changes in behaviour, then autopsied after death. Brodifacoum caused haemorrhaging and death in both species, and although each showed marked changes in behaviour and pathology, they differed in character, time of onset and duration. Results may be explained in part by species differences in behaviour and half-lives of blood clotting factors.
\end{abstract}

Keywords: brushtail possum, rat, anticoagulant pesticide, behaviour, pathology.

\section{INTRODUCTION}

Brodifacoum is an anticoagulant vertebrate pesticide used worldwide to control a variety of rodents. In New Zealand, it is incorporated in cereal baits for rat and possum control. It interferes with normal blood clotting by preventing vitamin $\mathrm{K}$ recycling (Fig. 1), which prevents the conversion of inactive precursors into active vitamin K-dependent blood-clotting factors (Thijssen 1995). Major haemorrhaging and death by respiratory or heart failure are well-documented outcomes.

Increasing attention to animal welfare issues worldwide, coupled with the new, more powerful Animal Welfare Act 1999, has required assessment of the humaneness of current pest control methods. Brodifacoum has been considered inhumane by some (see Kirkwood et al. 1994), but not all authors agree (Rowsell et al. 1979). Thorough humaneness assessments should include behavioural, physiological and pathological measurements. Work on trap humaneness is abundant (e.g. Warburtonet al. 2000), but only recently has attention focused on the humaneness of poisons for rats or possums (Gregory et al. 1998). This paper focuses on part of our work on the humaneness assessment of poisons used in New Zealand. The efficacy and effects of a lethal dose of brodifacoum on the behaviour, pathology and time until death is compared between Norway rats (Rattus norvegicus) and brushtail possums (Trichosurus vulpecula).

\section{Animals and housing}

\section{METHODS}

Wild-trapped possums of mixed age and laboratory-bred Norway rats aged 14 weeks, were individually caged with free access to water, fruit and cereal feed pellets, except during brodifacoum exposure when cereal feed pellets were withheld from possums. Rats and possums were kept in separate, temperature-controlled rooms, and acclimatised for at least 6 weeks prior to experiments. Animals that did not die were euthanased with sodium pentabarbitone while under halothane/oxygen anaesthesia. All experiments were conducted with prior approval from the Landcare Research Animal Ethics Committee.

New Zealand Plant Protection 53:310-315 (2000) 

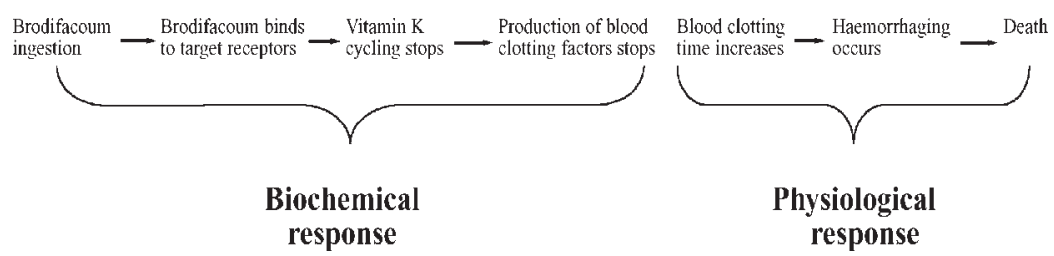

FIGURE 1: Time course of changes after brodifacoum ingestion.

\section{Brodifacoum treatment}

Animals were divided into two groups of 12 rats and two groups of 18 possums, each with equal numbers of males and females. One group of each species were not poisoned (controls) and the other group was treated with brodifacoum. Possums had free access to brodifacoum in cereal pellet baits (PESTOFFTM, Animal Control Products, Wanganui) nightly for 3 nights (days 0 - 2) to simulate exposure in the wild. The concentration of brodifacoum in baits, determined by high-performance liquid chromatography, was $16.6 \pm 1.3 \mathrm{mg} / \mathrm{kg}$. Bait intake was recorded each morning and fresh bait replaced each afternoon.

Rats were fed one wax bait containing approximately $50 \mathrm{mg}$ brodifacoum $/ \mathrm{kg}$ bait (Talon ${ }^{\circledR}$, ICI Cropcare, Richmond) on 1 evening. Baits were removed and intake recorded after $12 \mathrm{~h}$, or when rats had eaten $0.5 \mathrm{mg}$ brodifacoum $/ \mathrm{kg}$ body weight $\left(\mathrm{LD}_{90}\right)$.

\section{Behaviour}

To facilitate observations, possum nest boxes and rat nest box lids were removed and rooms kept in continuous light, beginning 5 days before exposure to brodifacoum (day -5). All animals were observed every 15 min for two periods each day and then every $15 \mathrm{~min}$ for $24 \mathrm{~h}$ during the predicted sickness period, in order to monitor behavioural changes more closely. At each 15-min observation, behaviour and clinical signs of poisoning were noted. Possums were observed between $0800-0845 \mathrm{~h}$ and 1900 - $2045 \mathrm{~h}$ from day -5 until day 16 , then for $24 \mathrm{~h}$ from day 17 until day 20 . Rats were observed between $0800-0845 \mathrm{~h}$ and $1900-2045 \mathrm{~h}$ from day -5 until day 5 , and for $24 \mathrm{~h}$ from day 6 until day 8 . Cereal feed pellet intake of all animals was recorded at the same time every morning from day -5 .

\section{Pathology}

All rats and 12 possums were chilled at $4{ }^{\circ} \mathrm{C}$ immediately after death and autopsied within $8 \mathrm{~h}$. Pathological changes, including internal and external haemorrhages and extravascular blood in body cavities, stifles and hip joints, were recorded.

\section{Statistics}

Statistical tests allowed for the sample number reducing over time, as animals died. Changes in the feed intake of rats and possums were analysed by fitting linear mixed-effect models by maximum likelihood using function lme in S-plus 4.5 (MathSoft Inc., Massachusetts). Models were compared using likelihood ratio tests. Bonferroni post-hoc tests were used to determine timing of feed intake changes.

\section{RESULTS}

Relative to bodyweight, rats consumed nearly twice as much brodifacoum as possums and died in around one-third the time (Table 1). All rats died, whereas two possums did not die and were euthanased on day 50.

\section{Behaviour changes}

Feed intake of both species declined after brodifacoum ingestion, differing significantly from that of controls, which remained constant (possums: $\chi^{2}{ }_{17}=29.31$, $\mathrm{P}<0.05$; rats: $\chi^{2}{ }_{13}=12.82, \mathrm{P}<0.001$ ). Thirteen days after initial exposure to brodifacoum (7 days before death), possum feed intake declined markedly, and was significantly reduced at day $15(t=4.63, \mathrm{P}<0.01)$. Similarly, rat feed intake declined significantly $(t=5.25, \mathrm{P}<0.001) 4$ days after brodifacoum ingestion ( 3 days before death). 
TABLE 1: Mean amounts of brodifacoum consumed, brodifacoum liver residue levels, times of behaviour changes and death and poison efficacy for possums and rats.

\begin{tabular}{lcc}
\hline Feature & Possums & Rats \\
\hline $\begin{array}{l}\text { Amount of brodifacoum consumed } \\
\text { (mg ai/kg body weight) }\end{array}$ & 0.88 & 1.56 \\
Amount of brodifacoum in liver & (range: $0.50-1.07)$ & (range: $0.94-2.02$ ) \\
(mg ai/g tissue) & 0.56 & 2.23 \\
Time of reduced feed intake & (range: $0.17-1.04)$ & (range: $0.70-3.45)$ \\
(days after initial ingestion) & 13 & 4 \\
Time of reduced activity & (6 days before death) & (3 days before death) \\
(days after initial ingestion) & 15 & 4 \\
Number of animals killed & (4 days before death) & (3 days before death) \\
Time until death & $16 / 18$ & $12 / 12$ \\
(days after initial ingestion) & 20.1 & 7.2 \\
& (range: $14.9-45.3)$ & (range: $5.6-8.5)$ \\
\hline
\end{tabular}

Rats and possums became less active and less reactive to stimuli after brodifacoum ingestion, showing increased lying and crouching (standing with bent legs and weight over forelegs, back hunched, abdomen tucked up and often with the head down) (Figs. 2 and 3). Behaviour of untreated possums and rats did not change throughout the experiment. During initial stages of poisoning, behaviour of poisoned rats and possums was similar to controls. Crouching and lying increased markedly in possums 15 days after initial exposure to brodifacoum ( 5 days before death). There was a corresponding drop in amount of time spent in a typical resting posture (curled) (Fig. 2). Poisoned rats also showed an increase in crouching and lying, and coincidentally

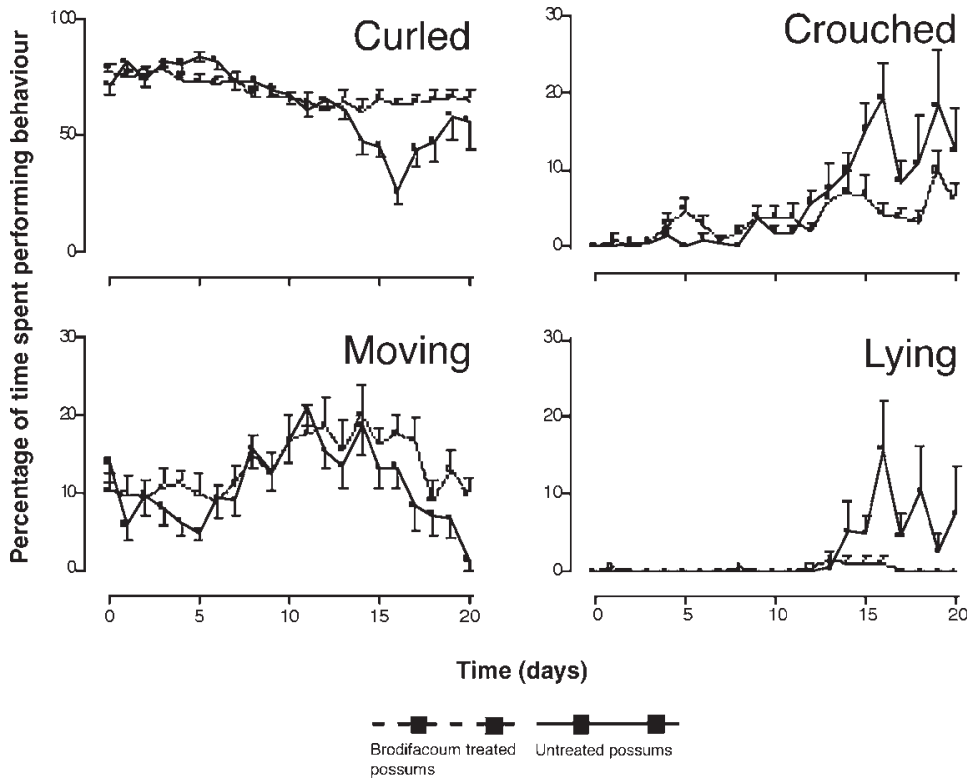

FIGURE 2: Percentage of time possums spent performing behaviours each day after initial brodifacoum ingestion (mean \pm SEM). Note different scales on y-axis. 

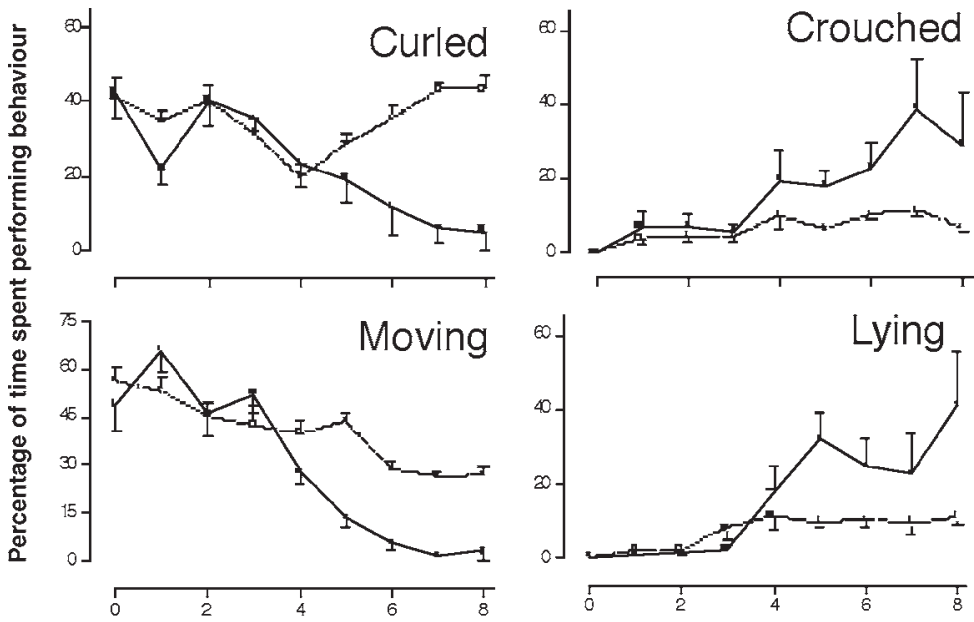

Tìme (days)

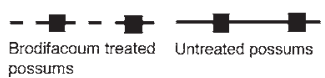

FIGURE 3: Percentage of time rats spent performing behaviours each day after brodifacoum ingestion (mean \pm SEM). Note different scales on $y$ axis.

less movement and time spent curled from 4 days after brodifacoum exposure ( 3 days before death) (Fig. 3). Throughout prolonged inactivity, poisoned rats and possums also had abnormal postures compared to untreated animals, and obvious clinical signs of poisoning. Clinical signs included external bleeding and pale extremities and were similar between rats and possums, except that four rats were affected by paresis then full paralysis of all limbs, which continued until death. Seven possums were also observed lying prostrate for an average of $2.32(0.25-6.25)$ hours before death and eight rats for $11.4(0.5-40.75)$ hours before death. Rats and possums remained conscious but unmoving during most of this period, except for some occasionally pushing or pulling themselves along the floor.

\section{Pathology}

Extensive intramuscular haemorrhaging was more severe and prevalent in rats $(8 / 12)$ than in possums (3/12). Main areas of haemorrhage in rats were subcutaneous and deep tissue in the thorax (10/12), limbs (7/12) and testes (5/12). By comparison, possums had most haemorrhaging in subcutaneous or deep tissues in the lumbar region (9/12), abdomen (6/12), lungs (8/12), heart (7/12), limbs (6/12), gut (6/12) and testes (4/12). Two rats and one possum had free blood within stifle or hip joints, respectively.

\section{DISCUSSION}

All rats and most possums poisoned with brodifacoum died. Two possums that did not die had ingested the lowest and third-lowest brodifacoum doses. However, dose may not be the only factor responsible since other studies have shown wide individual variation in time until death and efficacy within a dose range similar to that in our experiment (Eason and Jolly 1992).

Both species had a period of normal behaviour after poisoning, followed by a reduction in feed intake at the onset of apparent sickness. During sickness, rats and possums were less active (Figs 2 and 3), and often adopted abnormal postures. Similar 
signs in rats given anticoagulants have been reported elsewhere (Rowsell et al. 1979; Cox and Smith 1992). Possums did not develop the paralysis evident in four of the 12 rats. Rats were in bigger cages relative to their size than possums and were more active, often climbing and jumping. It is possible this caused haemorrhaging around the spine, which could not be easily seen at autopsy.

Possums took nearly three times longer to die than rats. The onset of sickness also occurred later in possums and the duration of the sickness period was longer (up to 5 days) than in rats (up to 3 days). Times until death are similar to those reported previously for rats (Redfern et al. 1976; Cox and Smith 1992) and possums (Eason and Jolly 1992). The species variation in time until death and duration of sickness could be explained by species differences in dose, biochemical response to brodifacoum (including poison absorption, distribution, metabolism and excretion) (Fig. 1), physiological response to brodifacoum or behaviour.

Dose may be responsible for the observed species variation since rats received a dose twice that of possums relative to bodyweight. However, rats that received similar doses of brodifacoum to possums in this study and in one other (Eason and Jolly 1992) still had relatively shorter times until death. Furthermore, Bachmann and Sullivan (1983) could not establish a relationship between brodifacoum dose and time when clotting factor synthesis was reduced in rats. It is possible dose is not important above a threshold level adequate to reduce blood clotting.

Eason et al. (1996) demonstrated that possum blood-clotting time began increasing 2 days after brodifacoum treatment, but was only significantly higher than pretreatment values after 7 days, whereas clotting time peaks within $24 \mathrm{~h}$ in rats (Mosterd and Thijssen 1991). If the biochemical response duration (Fig. 1) was prolonged, time until death may be extended. There is no evidence that brodifacoum absorption or distribution differs between rats and possums (Bachmann and Sullivan 1983; Eason et al. 1996) and in common with similar anticoagulants, brodifacoum is not significantly metabolised by mammals (Bachmann and Sullivan 1983). In addition, the rate of elimination is unlikely to be important since death occurs in both species before poison levels are reduced enough to have an effect on time of death (Bachmann and Sullivan 1983; Eason et al. 1996). Once brodifacoum binds to liver, vitamin K cycling and conversion of inactive blood-clotting factors to active factors are likely to stop rapidly, since both processes involve biochemical reactions. Accordingly, these probably do not contribute to species differences in time until death.

By contrast, physiological response time is affected by current levels and halflives of clotting factors in liver (Thijssen 1995) and may be prolonged if alternative, non-vitamin K-dependent clotting factors are utilised to maintain blood clotting (Kerins and MacNicoll 1999). The half-lives of possum vitamin K-dependent bloodclotting factors have not been determined, but evidence suggests they are longer in possums than rats (Eason et al. 1996; Kerins and MacNicoll 1999). The lag between the reduction in blood-clotting time and haemorrhage is likely to be similar, at around 2 days for both species (Hermann and Hombrecher 1962; K. Littin, unpubl. data). However, the lag between haemorrhage onset and death is longer in possums at around 12 days, than in rats (K. Littin, unpubl. data). Possums may have a mechanism to cope with low blood volume (which leads to death), such as can occur in extreme dehydration, if they have evolved to survive arid conditions in Australia.

Species differences in behaviour could affect time until death and duration of suffering by affecting haemorrhage severity and location. For example, we would expect a more severe haemorrhage to cause faster blood loss and hence a shorter time until death. Both species had mild to marked haemorrhaging, but sites of more severe haemorrhaging differed. The site of haemorrhages may be affected by direct abrasion since possums had more haemorrhaging in the area under most pressure in the typical resting posture (lumbar region), compared to rats, which were more active (particularly jumping and climbing) and had most damage in the thorax. Similarly, penned, brodifacoum-poisoned possums in a previous experiment, which jumped and climbed more than caged possums in the current experiment, had more severe haemorrhaging in the thorax and little damage in the lumbar region (K. Littin, unpubl. data). 
In conclusion, brodifacoum killed both rats and possums and caused marked changes in behaviour and pathology. However, the changes differed in character between species and behavioural changes occurred later and lasted for longer in possums. Our data suggest there is a prolonged period of sickness during brodifacoum poisoning when rat and possum welfare may be compromised. Details will be published elsewhere. The welfare of poisoned animals could be practically improved by shortening the time until death using drugs that potentiate anticoagulant action (Bachmann and Sullivan 1983). We intend to pursue this and other options to improve the humaneness of brodifacoum.

\section{ACKNOWLEDGEMENTS}

We thank Lynne Milne, Andrea Rhodes, Penny Willcock and Nicola Watkinson for technical help; Jim Hutton, Donald Arthur and Mark Wickstrom for advice on pathology; Wendy Ruscoe for statistical assistance; Chris Bailey, Lynn Booth and Kathryn O'Halloran for comments on the manuscript; and Christine Bezar for editorial assistance. This project was funded by the Foundation for Research, Science and Technology.

\section{REFERENCES}

Bachmann, K.J. and Sullivan, T.J., 1983. Dispositional and pharmacodynamic characteristics of brodifacoum in warfarin-sensitive rats. Pharmacology 27: 281288.

Cox, P.R. and Smith, R.H., 1992. Rodenticide ecotoxicology: pre-lethal effects of anticoagulants on rat behaviour. Pp 165-170 In: Proceedings of the 15 th vertebrate pest conference. J.E. Borrecco and R.E. Marsh (Eds); University of California, Davis.

Eason, C.T. and Jolly, S.E., 1992. Palatability and toxicity of brodifacoum paste to the possum. Forest Research Institute Report FWE 92/4:1-8; Forest Research Institute, Christchurch, New Zealand.

Eason, C.T., Wright, G.R. and Batcheler, D., 1996. Anticoagulant effects and the persistence of brodifacoum in possums (Trichosurus vulpecula). N.Z. J. Agric. 39: 397-400.

Gregory, N.G., Milne, L.M, Rhodes, A.T., Littin, K.E., Wickstrom, M. and Eason, C.T., 1998. Effect of potassium cyanide on behaviour and time to death in possums. N.Z. Vet. J. 46: 60-64.

Hermann, G. and Hombrecher, S., 1962. Control of rats and mice with racumin 57 products. P. Flanzenschatz - Nachrichten "Bayer” 15: 89-108.

Kerins, G.M. and MacNicoll, A.D., 1999. Comparison of the half-lives and regeneration rates of blood clotting factors II, VII, and $\mathrm{X}$ in anticoagulant-resistant and susceptible Norway rats (Rattus norvegicus Berk.). Comp. Biochem. Physiol. 122C: 307-316.

Kirkwood, J.K., Sainsbury, A.W. and Bennett, P.M., 1994. The welfare of free-living wild animals: methods of assessment. Anim. Welfare 3: 257-273.

Mosterd, J.J. and Thijssen, H.H.W., 1991. The long-term effects of the rodenticide, brodifacoum, on blood coagulation and vitamin $\mathrm{K}$ metabolism in rats. $\mathrm{Br} . J$. Pharmacol. 104: 531-535.

Redfern, R., Gill, J.E. and Hadler, M.R., 1976. Laboratory evaluation of WBA 8119 as a rodenticide for use against warfarin-resistant and non-resistant rats and mice. J. Hyg. 77: 419-426.

Rowsell, H.C., Ritcey, J. and Cox, F., 1979. Assessment of humaneness of vertebrate pesticides. Pp 236-249In: Proceedings of the Canadian Association for Laboratory Animal Science. The Canadian Association for Laboratory Animal Science, Calgary, Canada.

Thijssen, H.H.W., 1995. Warfarin-based rodenticides: mode of action and mechanism of resistance. Pestic. Sci. 43: 73-78.

Warburton, B., Gregory, N.G., and Morriss, G., 2000. Effect of jaw shape in kill-traps on time to loss of palpebral reflexes in brushtail possums. J. Wildl. Dis. 36: 92-96. 